Wood ${ }^{1}$ describes two examples-one in a girl aged 5 , another in a boy aged 7 -ot this anomaly as follows:

On the right side of the pharynx, projecting at times almost to the median line, is a large pulsnting vessel about the size vessel-pencil. J3y forcibly depressing the tongue, this bloodinward can be seen running from below upward and slightly whence until it reaches a point about opposite the uvula, whence it takes a course slightly outward and upward.

A similar case has been observed by A. Brown Kelly. ${ }^{2}$ Sack $^{3}$ found in a girl aged 10, who complained of throat whible of long duration, a strongly pulsating carotid which coursed with a slight curve directly under the mucous nembrane from below upward. Thompson* mentions a woman, aged 29 , who suffered from catarrhal laryngitis, and in whom lie found a strongly pulsating, lar'ge carotid artery on the left side immediately beneath the mucous membrane. Hulke reports an example of great tortuosity of the common carotid artery simulating an aneurysm, and states that such looping of the carotid has been noticed more often at its upper part just before the artery enters the skull. McBride ${ }^{0}$ writes

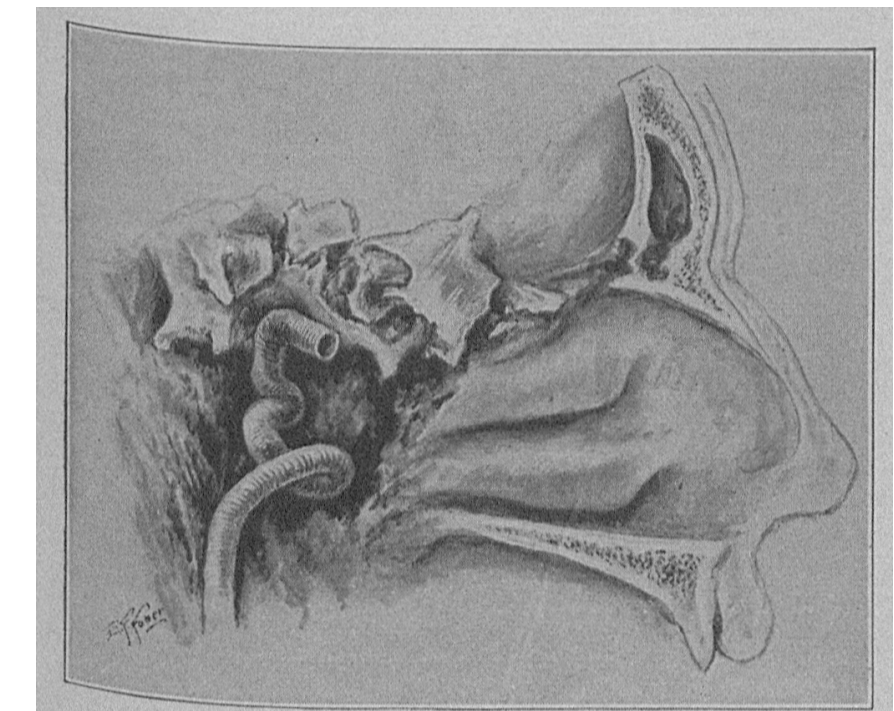

relation tortuosity of left internal carotid. Pharynx removed, but ation to palate can be seen.

of a case in which the posterior palatine pillar seemed to pulsate, and in which a large vessel was found immediately behind, and a systolic bruit was audible.

As regards sex, Morit\% Schmidt? states that this menaly is observed more frequently in women than in men. As to lirequency, Demme, who for ten years had looked for vascular anomalies in the pharynx at the patiost of Waldeyer and Fraenkel, saw, in 10,000 patients, pulsations of the pharyngeal wall in 2 per cent. He has seen anomalous carotids extending as vascular phas distinctly visible on the posterior wall of the pharynx between the vertebral column and the pharynthe mucosa, although usually this vascular arch lies at so level of the apex of the tonsillar recess, appearing omewhat belind the tonsil from the side and visible as far as the torus eustachius. Often, he says, the coil

1. Wood: Am, Jour. Med. Sc., 1002, n. s., cxxiv, 478.

Dlseaselly, A. Brown : Cited by Burnett. Ingris, Newcomb in 8. Sael of r, Nose and Thront, 1001, p. 488 .

8. Sack : Monatschr. f. Ohrenh., 1007 , xil, 277 .

5. Thompson: Milwaliee Med. .Jour., 1898, vi, 12.

6. Hulke: Loncet. Iondon, $1893,1,1385$.

6. MeBrlde: Edinburgh Med. Jour, December, 1806, p. 510

1008 . Schmldt, Moritz: Die Erkrankheiten der oberen Luptwege,

8. Demme: Wlen. med. Wehnschr., 1001, 11, 48, 2245. begins to be distinctly visible at the level of the sinus pyriformis, but rarely extends beyond the fossa of lRosenmiiller. He luas often observed both internal carotids bent inwardly in stch a way that at the pulsebent-both bends approached each other. Objective symptoms noted were tickling in the throat; ${ }^{3}$ sensation of a movable foreign body;" and tinnitus compared to the hissing of escaping steam. ${ }^{10}$

'l'he practical lesson this report teaches is to "stop, look and listen" before operating on any part of the pharymx. Since this anomaly may be present in any given case, thorough ocular and digital exploration of the pharymx for arterial pulsations must never be omitted. In case operation is indicated in the presence of this anomaly, preliminary ligature of the internal carotid opposite the upper border of the thyroid cartilage should be made. If doulst arises as to whether the anomalous artery is the ascending pharyngeal or the internal carotid, the common carotid artery should be oceluded in the same situation with a Matas metal clip. If the artery be discovered and damaged during an operation, control of the situation may be effected by compressing the common carotid artery against Chassaignac's tubercle (the prominent anterior tubercle of the transverse process of the sixth cervical vertebra), and ligation then performed.

241 South Thirteenth Street.

\section{PERSISTENT HYALOID ARTERY *}

\section{M. BOWES, M.D.} CHICAgo

There is no doubt that many cases of persistent hyaloid artery are unrecognized, and it is my object, as a general practitioner, to report a case as an aid to the pediatrician or the general practitioner who first sees one of these cases and may be at a loss to account for the complaint of a shadow or dark object floating before the eye, as well as the persistent headache or ocular pain which may accompany this condition. Or, as in the case which I shall report, a young child may shake its head to get the loose end of a persistent hyaloid artery out of the line of vision. There is usually defective vision, althougl Krauss ${ }^{1}$ found the vision normal in both eyes of a colored woman aged 41 , who complained of a dark object floating betore her eyes, which she had noticed for three weeks. She also had symptoms of accommodative wealiness, associated with headache and ocular pain.

In fetal life the hyaloid artery is continuous with the central artery of the optic nerve, generally extending as a single artery through the hyaloid canal to the posterior pole of the lens, where it branches into smaller vessels which supply the posterior vascular sheath of the lens. Instead of continuing as a single artery through the hyaloid canal it may divide several times. The artery does not usually extend to the center of the posterior pole of the lens, but a little to one side.

Fuchs ${ }^{2}$ states that of the hyaloid artery normally the only thing that is left in the new-born is a short and slender cord which disappears during the first year of life.

9. Kyle: Dlseases of Nose and 'J'hroat, 1000, p. 479.

10. Burnett, Ingals, Newcomb: Inseases of War, Nose and Throat, 1001 , p. 488 .

* Ifead bxiore the Chlengo I'ediatilc Soclety, Nov. 19, 1012

1. Kruuss: Ophth. IRec., $A$ prll, 1907.

2. Fuchs: Text-30ok of Opilthilmology, Ed. 4, 1911, p. 534. 
Shoemaker" reported a cuse of persistent hyaloid artery in both ejes. Ruewand ${ }^{4}$ observed in a man aged 31 not only the stem of the liyaloid artery, but also its distribution on the posterior capsule of the lens in form of a network of fine whitish thrends, and the remnants of two blood-ressels of the vitreous branching oft from a swelling of the stem of the artery, one upward and outward, the other downward and inward.

There may be other abnormalities present, as in the interesting case reported by Gïrtner. ${ }^{5}$ The patient was a girl aged 18 who had a bridge-coloboma of the iris and chorioid, accompanied by amblyopin, nystagmus; strabismus, deformity of the cornea with microcornea and microphthalmos.

The various anomalies are classified by Norris and Oliver ${ }^{6}$ as follows:

1. The whole artery, with a cellular sheath around the posterior part of it, may remain as in the fetal eye, and continue to carry blooi.

2. The artery may persist as a band through its whole length, but does not carry blood.

3. There may be a remnant of the artery attached to the optic disk which ends in a free extremity in the vitreous, and in which there is also an opacity at the back of the lens. The remnant attached to the disk is often a long, thin cord which is seen by the ophthalmoscope to lash about in an undulating way on movement of the eye.

4. The lenticular end of the artery may alone remain, its lindmost end being free and mobile in the vitreous. It is a variety which is rarely encountered. DeBeck ${ }^{7}$ could find only eight recorded cases of it.

5 . The neural end of the artery remains, the lenticular extremity having completely disappeared. This is the commonest variety of any. With the ophthalmoscope a thin, narrow cord is seen attached by one end to the optic disk, the other end being free in the vitreous. The free end may be knob-like or tapering. It generally oscillates with an undulating motion on movement of the eye, but occasionally is fixed and immobile.

6. The artery may become obliterated, but the sheath may remain as fibrous membranes or shreds of tissue attached to the optic disk filling up the depression normally left in the nerve-head by the divergence of the nerve-fibers.

7. Little rounded bodies of a steel-gray color, which appear to be fluid-containing cysts attached to the optic disk, are occasionally met as a congenital abnormality, and must in some way be connected with the fetal vascular apparatus for the persistent sheath of cystic distentions of the artery itself.

8. Some observers have seen appearances in the vitreous which they have thought pointed to persistence of the hyaline canal in which the artery lies, it and its cellular sheath having disappeared.

9. Many of the congenital opacities at the posterior pole of the lens are probably due to persistence of portions of the fibrovascular sheath of the lens, the vessels of which are derived in the fetal state from the division of the central hyaloid artery.

\section{REPOI'Y OF A CASE}

In 1910 I was called to see Miss $K$. C., aged 13, who had been having persistent headaches ever since early childhood.

3. Shoemnker: Ann. Ophth., April, 1906.

4. luewnud : Ztschr. f. A ugenh., 1000, p. 245.

5. Giltriner, C. : Beitr. z. Augenh., 1000, lxxiv, 232.

6. Norr's und oliver: Systen of Disease of the Sye, 1807, 1, 454.

7. DeBeck: Pelsistent Remalns of the Fetal Hyaloid Artery, Am. Ophth. Mouog., Cinclunat1, 1890-1891, 111, 1 .
There never had been any ocular pain. The sight in the left eye was much impared and if the right eye was covered the putient could read only the large and heavy letters of the headlines of the daily papers, while the small or fine print could not be seen.

The patient also complained of a shadow which kept movins in front of the left eye. This was not so noticeable whet using both eyes, but if the right eye was covered it was quite marked,

The father stated that when the patient was a baby, if bt would go into the room where she was sitting sle would shake her liead two or three times before recognizing hirb As the patient grew oller this jassed away.

The pust history of the patient is negative. The father is a strong, robust man who keeps a saloon, but is outside nost of the time doing mason and cement work. The mother is also in excellent henlth, but says that she has shadows pas hefore her eyes if slie rends very long or if the eyes get tired doing needle-work. Dr. F. I. IBrown examined her eyes, how ever, and found them normal except for accommodative weak ness.

I referred the patient to Dr. Brown, who examined the eyth thoroughly Sept. 15, 1910, and gave the following description of the conditions found:

"The external parts of both eyes are normal except for" mild form of conjunctivitis. Pupil reactions are normal light and accommodation. Cornea and iris normal.

"Examination of the interior of the eyes slows the righ" eye normal, and a posterior polar cataract in the left eye.

"In the vitreous chamber I find projecting from the disk long, slender object which moves freely in the vitreous whet the position of the eye is changed. This is attached by th posterior extremity to the optic disk and extends a little mor than half way to the posterior capsule of the lens. This con dition is known as persistent hyaloid artery and is quite fre quent. Its presence lowers the vision of the left ey to $20 / 200$, but vision is slightly improved with a +2 sphiort as her left eye is hypermetropic to that extent.

"The patient has one-half diopter of astigmatism in right eye, which probably accounts for her severe headache when she uses her eyes excernively."

6031 Circle Ávenue.

\section{REPORTS OF UTERINE MALFORMATIONS}

\section{E. M. PRINCE, M.D. BIRMINGIAM, ALA.}

Many text-books on gynecology assert that a double uterus, or the absence of the uterus, is a rare occurrence. This has not been my experience. Although my surgical work is confined entirely to private patients, I have seen half a dozen of these anomalies in the course of a few years, so that I can but wonder why in the large clinics embracing the enormous amount of charity and private surgical work, they should be classed "extremely rare."

These malformations are caused by developmental defects in the early embryonic stage. The vagina $a^{\text {nd }}$ uterus are both developed by the coalescence of the lower two-thirds of the müllerian ducts, and the absorp tion of their inner wall. If these ducts fail to unite or the septum is not absorbed, a deformity results to more or less extent. If the ducts unite and the septum persists there will be a double cavity, but the uterus is normal externally. If the ducts do not unite at all, there will be two separate uterine bodies. The absenct of a uterus is said by Kelly and other writers to be al "extremely rare condition." This malformation caused by the absence or the imperfect development the muillerian ducts. 